\title{
Enteroaggregative Escherichia coli is associated with antibiotic resistance and urinary tract infection symptomatology
}

\author{
Verónica I Martínez-Santos ${ }^{1}$, María Ruíz-Rosas ${ }^{2}$, Arturo Ramirez- Peralta ${ }^{3}$, Oscar Zaragoza García ${ }^{4}$, Luis \\ Armando Rezendiz-Reyes ${ }^{4}$, Obed Josimar Romero-Pineda ${ }^{4}$, Natividad Castro-Alarcón ${ }^{\text {Corresp. } 4}$ \\ ${ }^{1}$ Cátedras CONACYT, Universidad Autónoma de Guerrero, Chilpancingo, Guerrero, México \\ Laboratorio clínico, área Microbiología, Clínica Hospital ISSSTE Chilpancingo, Chilpancingo, Guerrero, México \\ 3 Laboratorio de Patometabolismo Microbiano, Facultad de ciencias Químico Biológicas, Universidad Autónoma de Guerrero, Chilpancingo, Guerrero, \\ México \\ 4 Laboratorio de investigación en Microbiología, Facultad de Ciencias Químico Biológicas, Universidad Autónoma de Guerrero, Chilpancingo, Guerrero, \\ México \\ Corresponding Author: Natividad Castro-Alarcón \\ Email address: natividadcastro24@gmail.com
}

Background. Uropathogenic Escherichia coli (UPEC) is the causative agent of uncomplicated urinary tract infections (UTIS) in ambulatory patients. However, enteroaggregative E. coli (EAEC), an emergent bacterial pathogen that causes persistent diarrhoea, has recently been associated with UTIs. The aim of this study was to determine the frequency EAEC virulence genes, antibiotic resistance, as well as biofilm production of UPEC isolates obtained from ambulatory patients with non-complicated UTIs that attended to the ISSSTE clinic in Chilpancingo, Guerrero, Mexico, and correlate these with the patients' urinary tract infection symptomatology.

Methods. 100 clinical isolates were obtained. The identification of clinical isolates, antimicrobial susceptibility testing, and extended spectrum beta-lactamases (ESBLs) production were performed using the Vitek automated system. Assignment of $E$. coli phylogenetic groups was performed using the quadruplex phylo-group assignment PCR assay. UPEC virulence genes ( $h l y A$, fimH, papC, iutA, and cnf1) and EAEC virulence genes (aap, aggR, and aatA) were detected by multiple PCR.

Results. We found that $22 \%$ of the isolates carried the aggR gene and were classified as UPEC/EAEC. The main phylogenetic group was B2 (44.1\% were UPEC and $77.27 \%$ UPEC/EAEC isolates, respectively). Over half of the UPEC/EAEC isolates (63.64\%) were obtained from symptomatic patients, however the aatA gene was the only one found to be associated with the risk of developing pyelonephritis $(O R=5.15$, $p=0.038$ ). The $77.71 \%$ of the UPEC/EAEC isolates were ESBL producers and $90.91 \%$ multidrug-resistant (MDR). In conclusion, UPEC/EAEC isolates are more frequent in symptomatic patients and the aat $A$ gene was associated with a higher risk of developing pyelonephritis, along with UPEC genes hlyA and cfnl. UPEC/EAEC isolates obtained from UTI showed ESBL production and MDR. 
1 Enteroaggregative Escherichia coli is associated with antibiotic resistance and urinary tract

2 infection symptomatology

3

4

5

6

Verónica I. Martínez-Santos ${ }^{1}$, María Ruíz-Rosas ${ }^{2}$, Arturo Ramírez-Peralta ${ }^{3}$, Oscar ZaragozaGarcía $^{4}$, Luis A. Rezendiz-Reyes ${ }^{4}$, Obed J. Romero-Pineda ${ }^{4}$, Natividad Castro-Alarcón ${ }^{4}$.

${ }^{1}$ Cátedras CONACyT, Facultad de Ciencias Químico-Biológicas, Universidad Autónoma de Guerrero, Chilpancingo, Guerrero, México.

${ }^{2}$ Laboratorio clínico, Área Microbiología, Clínica Hospital ISSSTE Chilpancingo, Guerrero, México.

${ }^{3}$ Laboratorio de Patometabolismo Microbiano, Facultad de Ciencias Químico-Biológicas, Universidad Autónoma de Guerrero, Chilpancingo, Guerrero, México.

${ }^{4}$ Laboratorio de Investigación en Microbiología, Facultad de Ciencias Químico-Biológicas, Universidad Autónoma de Guerrero, Chilpancingo, Guerrero, México.

Corresponding Author:

Natividad Castro-Alarcón ${ }^{4}$

Av. Lázaro Cárdenas s/n, C.U. Sur, Col. Haciendita. C.P. 39090. Chilpancingo, Guerrero, México.

Email address: natividadcastro24@gmail.com

\section{Abstract}

Background. Uropathogenic Escherichia coli (UPEC) is the causative agent of uncomplicated urinary tract infections (UTIs) in ambulatory patients. However, enteroaggregative E. coli (EAEC), an emergent bacterial pathogen that causes persistent diarrhoea, has recently been associated with UTIs. The aim of this study was to determine the frequency EAEC virulence genes, antibiotic resistance, as well as biofilm production of UPEC isolates obtained from ambulatory patients with non-complicated UTIs that attended to the ISSSTE clinic in Chilpancingo, Guerrero, Mexico, and correlate these with the patients' urinary tract infection symptomatology.

Methods. 100 clinical isolates were obtained. The identification of clinical isolates, antimicrobial susceptibility testing, and extended spectrum beta-lactamases (ESBLs) production were performed using the Vitek automated system. Assignment of $E$. coli phylogenetic groups was performed using the quadruplex phylo-group assignment PCR assay. UPEC virulence genes (hlyA, fim H, papC, iutA, and cnfl) and EAEC virulence genes (aap, aggR, and aatA) were detected by multiple PCR. 
37 Results. We found that $22 \%$ of the isolates carried the $\operatorname{aggR}$ gene and were classified as

UPEC/EAEC. The main phylogenetic group was B2 (44.1\% were UPEC and $77.27 \%$ UPEC/EAEC isolates, respectively). Over half of the UPEC/EAEC isolates (63.64\%) were obtained from symptomatic patients, however the aatA gene was the only one found to be associated with the risk of developing pyelonephritis $(\mathrm{OR}=5.15, \mathrm{p}=0.038)$. The $77.71 \%$ of the UPEC/EAEC isolates were ESBL producers and 90.91\% multidrug-resistant (MDR). In conclusion, UPEC/EAEC isolates are more frequent in symptomatic patients and the aatA gene was associated with a higher risk of developing pyelonephritis, along with UPEC genes $h l y A$ and $c f n 1$. UPEC/EAEC isolates obtained from UTI showed ESBL production and MDR.

\section{Introduction}

Urinary tract infections (UTIs), defined as the presence of $\geq 10^{5}$ colony-forming units (CFU) per $\mathrm{mL}$ of midstream urine, are one of the most common bacterial infections, affecting around 150 million people worldwide per year $(7,29)$. In Mexico, these infections were the third cause of morbidity in 2017 , with $4,474,599$ cases, and an incidence of 3,622.62/100,000 inhabitants. The most affected age group was 25 to 44 years old, with 1,344,198 cases, of which 1,094,069 were in women and 250,129 in men (27). UTIs occur mainly in women, of which around $60 \%$ are estimated to have an UTI at least once in their lifetime (29). Although women are affected in a ratio 8:1 with respect to men, these infections are also an important cause of morbidity in young boys and older men (7). Some medical conditions can predispose or favor the occurrence of UTIs, like type 2 diabetes, which seems to increase the incidence of symptomatic infections (22, 10); and pregnancy, which makes women more sensitive to this infection (4). UTIs are classified as uncomplicated or complicated depending on the absence or presence, respectively, of structural abnormalities on the urinary tract (34). These infections can present as asymptomatic bacteriuria, which is defined by the presence of a positive urine culture with $10^{5} \mathrm{CFU} / \mathrm{mL}$ but without symptoms, or as symptomatic infections, which produce dysuria with or without frequency, urgency, and pain (8).

UTIs are primarily caused by Escherichia coli, a Gram-negative bacterium that is part of the intestinal microbiota. This bacterium is the main etiological agent of UTIs, being responsible for $75-95 \%$ of the cases (9). Although E. coli is usually a commensal organism, there are several pathotypes that cause intestinal and extra intestinal diseases. E. coli strains that cause intestinal diseases are known as diarrhoeagenic $E$. coli (DEC), and are classified into 6 different pathotypes, named: enteropathogenic E. coli (EPEC), enterohaemorrhagic E. coli (EHEC), enterotoxigenic $E$. coli (ETEC), enteroinvasive $E$. coli (EIEC), diffusely adherent $E$. coli (DAEC), and enteroaggregative E. coli (EAEC). Extra-intestinal E. coli (ExPEC), on the other hand, include avian pathogenic E. coli (APEC), meningitis/sepsis-associated E. coli (MNEC), and uropathogenic E. coli (UPEC) (18).

UPEC is the main etiological agent of UTIs, both community-acquired and nosocomial, causing around $90 \%$ and $50 \%$ of the cases, respectively; followed by Klebsiella pneumoniae, 
75

76

77

78

79

80

81

82

83

84

85

86

87

88

89

90

91

92

93

94

95

96

97

98

99

100

101

102

103

104

105

106

107

108

109

110

111

Enterococcus faecalis, Proteus mirabilis, Pseudomonas aeruginosa, and Staphylococcus aureus, among others (7). The virulence potential of UPEC is determined largely by the presence of several virulence factors, among which are adhesins, toxins, and siderophores. Some of the virulence factors that help UPEC to overcome host defenses and establish infection are type I and $\mathrm{P}$ fimbriae (encoded by the fim and pap operons, respectively), the alpha-haemolysin (encoded by $h l y A$ ), the ferric aerobactin receptor (encoded by $i u t A$ ), and the cytotoxic necrotizing factor 1 (encoded by chfl) (17).

In recent years, the diarrheagenic pathotype EAEC has also been identified as a causative agent of UTIs $(25,24,13,33,26)$. EAEC is usually the etiological agent of acute and persistent diarrhea in developing countries, also affecting people who travel to these countries, causing traveler's diarrhea (11). The main molecular characteristic of EAEC is the presence of the virulence plasmid pAA. This plasmid carries predictor genes aatA (previously known as CVD432 probe, which codes for a TolC-like outer membrane protein) and $\operatorname{agg} R$ (which codes for the master regulator AggR); along with other EAEC genes, like aap (dispersin gene), pet (plasmid-encoded toxin gene) and several aggregative adherence fimbriae genes. However, given the genetic plasticity of EAEC, some strains carry plasmids with different number and combination of genes $(23,19)$.

Phylogenetically, E. coli can be divided into eight phylogroups, of which seven are E. coli sensu stricto (A, B1, B2, C, D, E, F), and one is the Escherichia cryptic clade I (3). Extraintestinal E. coli strains, including UPEC, belong mainly to phylogroups B2 and D, whereas EAEC strains have been found to be in phylogroups A, B1, B2, and D, suggesting that EAEC strains are phylogenetically diverse and originate from multiple lineages $(5,16)$. The aim of this study was to determine the frequency EAEC virulence genes, antibiotic resistance, as well as biofilm production of UPEC isolates obtained from ambulatory patients with non-complicated UTIs that attended to the ISSSTE clinic in Chilpancingo, Guerrero, Mexico, and correlate these with the patients' urinary tract infection symptomatology.

\section{Materials and Methods}

\section{$E$. coli isolates, antibiotic susceptibility testing, and ESBL production}

Samples were collected from November 2016 to March 2017 and only one isolate per patient was examined. Urine samples from 100 ambulatory patients with community acquired UTIs attending the ISSSTE clinic in Chilpancingo, Guerrero, Mexico where analyzed. The study was approved by the Research Ethics Committee of the Autonomous University of Guerrero (CB002/2021) and the Ethics Committee of the ISSTE clinic. All participants agreed to participate and gave their informed consent in writing.

The urine cultures were processed using conventional methods and included samples with a viable count of $>10^{5} \mathrm{CFU} / \mathrm{mL}$. The antibiotics assayed in the susceptibility test were ampicillin, ampicillin/sulbactam, cefazolin, ceftriaxone, cefepime, aztreonam, amikacin, gentamicin, 
112 tobramycin, ciprofloxacin, nitrofurantoin, and trimethoprim/ sulfamethoxazole. Isolates with a

113 resistance to three or more antibiotics were classified as multidrug-resistant (MDR). The

114 identification of clinical isolates, antimicrobial susceptibility testing, and ESBLs production

115 detection were performed using the Vitek2 automated system (BioMérieux) and AST-GN70

116 cards (Lot Number 590357210), and biochemical test.

\section{Conventional phylogenetic grouping}

118 Total DNA extraction and assignment of E. coli phylogenetic groups (A, B1, B2, C, D, E, F and

119 Clade I) by the quadruplex phylo-group assignment PCR assay described by Clermont et al. (3)

120 were performed as described previously (12).

\section{Detection of virulence genes of the isolates}

122 UPEC virulence genes hlyA (alpha-hemolysin), fimH (type 1 fimbriae), papC (P-fimbriae), iut $A$

123 (ferric aerobactin receptor), and cnfl (cytotoxic necrotizing factor 1) were detected by PCR using

124 primers listed in Table 1. The reaction was performed in a final volume of $25 \mu \mathrm{L}$, containing

$12512.5 \mu \mathrm{L}$ Go Taq Green Master Mix (Promega), $100 \mathrm{ng}$ of DNA, and $0.6 \mu \mathrm{M}$ of each primer. The

126 amplification conditions were: 1 cycle at $94^{\circ} \mathrm{C}$ for $5 \mathrm{~min}, 25$ cycles at $94^{\circ} \mathrm{C}$ for $30 \mathrm{sec}, 63^{\circ} \mathrm{C}$ for

$12730 \mathrm{sec}$, and $72^{\circ} \mathrm{C}$ for $3 \mathrm{~min}$, and $1 \mathrm{cycle}$ at $72^{\circ} \mathrm{C}$ for $10 \mathrm{~min}$ in a thermal cycler (Bio-Rad). The

128 amplified products were analyzed by agarose gel electrophoresis (1.5\%) stained with ethidium

129 bromide and visualized in an ultraviolet transilluminator.

130 EAEC virulence genes aap (dispersin), $\operatorname{agg} R$ (transcriptional regulator), and the AA probe were

131 detected by PCR using primers listed in Table 1. The reaction was performed in a final volume

132 of $12.5 \mu \mathrm{L}$ containing $100 \mathrm{ng}$ DNA, $15 \mathrm{pmol}$ of each oligonucleotide, and $5 \mu \mathrm{L}$ of Go Taq Green

133 Master Mix (Promega). The conditions used were 1 cycle at $94^{\circ} \mathrm{C}$ for $5 \mathrm{~min}, 25$ cycles at $94^{\circ} \mathrm{C}$

134 for $30 \mathrm{sec}, 63^{\circ} \mathrm{C}$ for $30 \mathrm{sec}$ and $72^{\circ} \mathrm{C}$ for $3 \mathrm{~min}$, and a final cycle at $72^{\circ} \mathrm{C}$ for $10 \mathrm{~min}$ in a thermal

135 cycler (Bio-Rad). The amplified products were analyzed by polyacrylamide gel electrophoresis

$136(6 \%)$ stained with silver nitrate.

\section{Biofilm quantification}

138 Biofilm formation was determined by the quantitative method in 96-well polystyrene

139 microplates. Briefly, 3 colonies were cultured in $3 \mathrm{~mL}$ of BHI broth and incubated for $2 \mathrm{~h}$ at

$14037^{\circ} \mathrm{C}$. The optical density (OD) of the culture was measured at $630 \mathrm{~nm}$, fresh BHI media was

141 inoculated adjusting the inoculum to an $\mathrm{OD}_{630}$ of 0.15 , and incubated for $24 \mathrm{~h}$ at $37^{\circ} \mathrm{C}$. After

142 incubation, $20 \mu \mathrm{L}$ of each culture were added to each well containing $180 \mu \mathrm{L}$ of LB broth

143 supplemented with $5 \%$ glucose. The microplate was then incubated for $24 \mathrm{~h}$ at $30^{\circ} \mathrm{C}$, and the

144 bacterial growth was quantified at $630 \mathrm{~nm}$ using a microplate reader. For biofilm quantification,

145 the supernatants were removed, and the wells were washed twice with sterile PBS $5 \mathrm{mM}$ and

146 dried at room temperature for $30 \mathrm{~min}$ and $200 \mu \mathrm{L}$ of crystal violet $1 \%$ was added for $15 \mathrm{~min}$. The

147 dye was removed, and the wells were washed again twice with PBS $5 \mathrm{mM}$ and dried for $20 \mathrm{~min}$.

148 Then, $200 \mu \mathrm{L}$ of $96 \%$ ethanol were added for $10 \mathrm{~min}$. Quantification was performed at a 
149 wavelength of $570 \mathrm{~nm}$ in a microplate reader (Multiskan Go, Thermo Scientific). The results are

150 the average of three independent experiments. The isolates were classified as low and high

151 biofilm producers (32).

152

153 Clinical characteristics

154 The classification of patients according to the type infections was performed considering the

155 clinical symptomatology. Cystitis was identified by typical clinical symptoms, including dysuria,

156 frequent voiding, and lower abdominal pain, whereas pyelonephritis was clinically identified by

157 fever, nausea, dysuria, urgent voiding, flank pain, and lumbar tenderness (6).

\section{Statistical analysis}

159 The statistical analyses were performed using the STATA V.13.0 software and GraphPad Prims

160 V.8.0. The frequencies were determined by Chi-square test and Fisher's exact test. The

161 regression model adjusted by age and gender were determined in the UPEC and EAEC with the

162 virulence genes and clinic symptomatology. Odds ratios (ORs), 95\% confidence intervals (CI),

163 and $p$ values were calculated. The $\mathrm{p}<0.05$ were considered statistically significant.

\section{Results}

165 Phylogenetic groups and presence of EAEC isolates among UPEC

166 A total of 100 clinical isolates were tested. PCRs were performed in order to determine the

167 phylogenetic group and to detect the virulence genes of each isolate. One of the isolates was

168 identified as E. albertii, so it was discarded. Of the 99 remaining isolates, 22 were classified as

$169 \mathrm{UEPC} / \mathrm{EAEC}$ due to the presence of the $\operatorname{aggR}$ gene, while the rest were classified as UPEC.

170 When the isolates were grouped according to the phylogenetic group, we found that most of the

171 isolates, both UPEC and UPEC/EAEC, belonged to the B2 group (44.1\% and 77.27\%,

172 respectively) (Fig. 1).

\section{Occurrence of UPEC and UPEC/EAEC in patients with different clinical symptoms and}

174 demographic characteristics

175 The distribution of the isolates was then analyzed according to the clinical and demographic

176 characteristics of the population in order to determine if there was a relation between these

177 characteristics and the pathotypes (Table 2 ). As expected, most of the isolates $(76.77 \%)$ were

178 obtained from female patients, both UPEC and UPEC/EAEC. Regarding patients' age, 59\% of

179 the UPEC/EAEC isolates were obtained from older adults, while $48 \%$ of the UPEC isolates were

180 obtained from elderly patients. Of all the isolates, $66.67 \%$ were obtained from patients with no

181 UTI-associated risk factors. The most frequent risk factor in our population was type 2 diabetes

182 (T2D), followed by T2D/chronic renal failure, chronic renal failure, catheter use and pregnancy.

183 No significant difference was found in the number of UPEC/EAEC and UPEC isolates obtained.

184 Interestingly, most of the UPEC/EAEC isolates (63.64\%) were isolated from patients with

185 clinical symptomatology, while most of the UPEC isolates $(59.74 \%)$ were obtained from

186 asymptomatic patients. This result suggests that UPEC/EAEC virulence genes seem to be 
187 associated with the presence of clinical symptoms. However, when we grouped the isolates

188

189

190

191

192

193

194

195

196

197

198

199

200

201

202

203

204

205

206

207

208

209

210

211

212

213

214

215

216

217

218

219

220

221

222

223

according to the type of infection, the same percentage of UPEC/EAEC isolates were isolated from patients with asymptomatic bacteriuria and cystitis (36.36\%).

\section{Occurrence of virulence genes in EAEC and UPEC isolated from asymptomatic and} symptomatic patients

Since apparently UPEC/EAEC isolates are more prevalent in patients with clinical symptoms, we wondered if any of the virulence genes detected could contribute to the clinical symptomatology. As seen in Table 3, the $\operatorname{aggR}$ gene was found to be more predominant in isolates obtained from patients with clinic symptomatology (31\%), while the gen aap $A$ was the less frequent (24\%); however, only the gen aat $A$ is more frequent in isolates from patients with clinical symptoms than without symptoms $(p=0.045)$. Regarding UPEC virulence genes, $h l y A$ and $c f n 1$ were also found to be more frequent in isolates from symptomatic patients when compared to the asymptomatic ones ( $p=0.005$ and 0.020$)$.

Then we wanted to determine if these genes were associated to clinical symptoms of cystitis or pyelonephritis. As seen in Table 4, none of the EAEC virulence genes were associated with symptoms of either infection, however the aatA gene seems to increase the risk of developing pyelonephritis $(\mathrm{OR}=5.15$, CI 95\%, 1.09-24.32, $p=0.038)$, while UPEC virulence genes $c n f 1$ and hly $A$ are associated with clinical symptoms of pyelonephritis $(\mathrm{OR}=4.22, \mathrm{CI} 95 \%, 1.30-13.64$, $p=0.016$ and $\mathrm{OR}=8.25$, CI 95\%, 1.83-37.21, $p=0.006$, respectively).

We also wanted to determine if the production of biofilm was associated with these symptoms, but only $21 \%(21 / 99)$ of the isolates were high biofilm producers, and of these, most of the isolates $(47.6 \%, 10 / 21)$ were isolated from patients with asymptomatic bacteriuria.

\section{Resistance pattern, ESBL and biofilm production}

The antibiotic susceptibility pattern of the obtained isolates was also analyzed. We found that $46.46 \%$ of our isolates were ESBL producers, and this result correlated with the resistance to cefazolin (52.53\%), ceftriaxone (47.47\%), cefepime (45.45\%), and aztreonam (47.47\%) (Table $5)$. The number of UPEC/EAEC isolates resistant to these antibiotics was higher than that of UPEC isolates. Also, there was statistically significant difference between UPEC/EAEC and UPEC in the resistance to tobramycin $(p=0.027)$ and ciprofloxacin $(p=0.040)$. However, there was no statistically significant difference in the resistance to aminoglycosides (amikacin and gentamycin) and trimethoprim/sulfamethoxazole. Seventeen percent of the isolates causing UTI were resistant to nitrofurantoin. Interestingly, more UPEC/EAEC isolates were shown to be MDR than UPEC isolates ( $p=0.017$ ). Regarding biofilm production, only $22.11 \%$ of the isolates were high producers.

\section{Discussion}

In this work, we demonstrated the importance of UPEC/EAEC isolates as the causative agent of community acquired UTI. Our results show that of 99 isolates obtained, 22 had the aggR EAEC 
224 gene, and so were considered UPEC/EAEC isolates. Previous reports have found a prevalence of

225

226

227

228

229

230

231

232

233

234

235

236

237

238

239

240

241

242

243

244

245

246

247

248

249

250

251

252

253

254

255

256

257

258

259

260

261

hybrid isolates of $3.5 \%$ based on the detection of the aatA and pap genes $(1,19)$. The phylogenetic analysis revealed that the UPEC/EAEC isolates were distributed in phylogroups A, $\mathrm{B} 1, \mathrm{~B} 2$ and $\mathrm{D}$, which is the distribution reported for EAEC strains (16). Most of the UPEC/EAEC isolates obtained in this work belonged to group B2. Our results show that the hybrid isolates obtained in this work are more diverse than those obtained from an outbreak in Copenhagen, Denmark in 1991, which belonged only to phylogroup A (24), and those recovered from Brazilian patients with UTI and bacteremia, which belonged only to phylogroups D and A (19). On the other hand, the UPEC isolates were found to be distributed in all the phylogenetic groups. Although it is considered that ExPEC strains belong to groups $\mathrm{B} 2$ and $\mathrm{D}$, and commensal strains are gathered in groups A and B1, we found relatively high percentages of UPEC isolates in groups A and B1, and lower percentages in groups C, E, F, and Clade I, showing that our isolates are highly diverse.

Regarding the clinical and demographic characteristics of our population, none of them seemed to favor the infection by UPEC/EAEC isolates over UPEC isolates, since the frequency of both was similar in both sexes, as well as in patients of different age groups and with different risk factors. Nonetheless we observed that the frequency of UPEC/EAEC isolates was slightly higher in patients with clinical symptomatology than the UPEC isolates, which were more frequent in asymptomatic patients. The presence of hybrid UPEC/EAEC strains in outbreaks of UTI has led to the assumption that EAEC virulence genes contribute to the virulence of the urinary strains (19). According to this, most of the UPEC/EAEC isolates were obtained from symptomatic patients, however, we could not relate UPEC/EAEC isolates with a specific infection.

With respect to the contribution of EAEC genes aap, aggR, and aatA to the virulence of the bacteria, it has been shown that these genes are present in EAEC isolates obtained from patients with diarrhea in frequencies similar or higher to the ones we found (aap 27-32\%, aatA 16-33\%, aggR 11-67\%), but they are absent or in low frequencies in EAEC isolates obtained from patients without diarrhea, supporting their role on the developing of the disease. Accordingly, the presence of two or three of these genes has been associated with diarrhea $(15,21,35,2)$.

The analysis of the distribution of the EAEC genes showed that the most frequent gene in our isolates was aapA, followed by aggR, and aatA. Despite this, the aatA gene was the only EAEC gene that was more frequent in isolates obtained from symptomatic patients. This gene codes for the protein dispersin, which has a role in the formation of a surface coat that mediates bacterial dispersion by avoiding the aggregation by the aggregative fimbriae (28). Probably, in the hybrid UPEC/EAEC isolates, it also contributes to the dispersion and helps in the establishment of a symptomatic infection. This could be accomplished with the presence of UPEC virulence genes, for example, $c f n l$ and $h l y A$, which we also found to be more frequent in isolates from symptomatic patients, and the three genes were determined to increase the risk of developing pyelonephritis. In fact, $c n f l$ and $h l y A$ have been shown to play a role in inflammation, and the

Peer) reviewing PDF | (2021:03:58585:1:1:NEW 10 Jun 2021) 
262 deletion of either one attenuates cystitis mediated by UPEC strain CP9 (30). Both genes have

263 been shown to be strongly associated in urinary strains (20), however only 13 of our isolates had

264 this combination. The interplay of $c n f 1, h l y A$ and aatA in the development of clinical symptoms

265 and pyelonephritis needs to be addressed in more detail.

266 Biofilm formation is an important characteristic of EAEC and UPEC strains. It is involved not

267 only in the persistence of the infections, but also contributes to bacterial resistance to antibiotics

$268(14,31)$. In this regard, most of the isolates obtained in this work were low biofilm producers,

269 and only $22.11 \%$ were high producers. Accordingly, biofilm production was not found to be

270 related to a specific infection or the risk of development. Neither we found differences in biofilm production between UPEC/EAEC and UPEC isolates.

272 Regarding antibiotic resistance, UPEC and UPEC/EAEC isolates showed a similar antibiotic

273 resistance profile, except for antibiotics cefazoline, ceftriaxone, cefepime, aztreonam,

274 tobramycin and ciprofloxacin; and a higher number of EAEC isolates were ESBL producers

275 (77.27\%). Also, more UPEC/EAEC isolates (90.91\%) were MDR than UPEC isolates (63.64\%).

276 This percentage is higher than those found in EAEC isolates obtained from patients with

277 intestinal infections in two different studies $(75 \%$ and $58 \%)(36,37)$. This suggests that these

278 isolates are more likely to acquire antibiotic resistance genes. To our knowledge, this is the first

279 report that analyses the antibiotic resistance in UPEC isolates containing EAEC genes. More

280 studies are needed to identify and monitor these bacterial isolates, which should be relevant in

281 clinical practice due to its potential pathogenic effect.

282 Conclusions

283 UPEC/EAEC isolates are more frequent in symptomatic patients and the aatA gene was associated 284 with a higher risk of developing pyelonephritis, along with UPEC genes hlyA and cfnl. 285 UPEC/EAEC isolates obtained from UTI showed ESBL production and MDR.

286

287

\section{Acknowledgments}

We thank José Gatica Bello for statistical analysis.

\section{References}

1. Abe, C. M., F. A. Salvador, I. N. Falsetti, M. A. Vieira, J. Blanco, J. E. Blanco, M. Blanco, A. M. Machado, W. P. Elias, R. T. Hernandes and T. A. Gomes (2008). "Uropathogenic Escherichia coli (UPEC) strains may carry virulence properties of diarrhoeagenic E. coli." FEMS Immunol Med Microbiol 52(3): 397-406.

2. Bamidele, O., Z. D. Jiang and H. Dupont (2019). "Occurrence of putative virulence-related genes, aatA, aggR and aaiC, of Enteroaggregative Escherichia coli (EAEC) among adults with travelers' diarrhea acquired in Guatemala and Mexico." Microb Pathog 128: 97-99. 
298

299

300

301

302

303

304

305

306

307

308

309

310

311

312

313

314

315

316

317

318

319

320

321

322

323

324

325

326

327

328

329

330

331

332

333

334

335

336

337

338

339

340

341

342

3. Clermont, O., J. K. Christenson, E. Denamur and D. M. Gordon (2013). "The Clermont Escherichia coli phylo-typing method revisited: improvement of specificity and detection of new phylo-groups." Environ Microbiol Rep 5(1): 58-65.

4. Delzell, J. E., Jr. and M. L. Lefevre (2000). "Urinary tract infections during pregnancy." Am Fam Physician 61(3): 713-721.

5. Escobar-Paramo, P., O. Clermont, A. B. Blanc-Potard, H. Bui, C. Le Bouguenec and E. Denamur (2004). "A specific genetic background is required for acquisition and expression of virulence factors in Escherichia coli." Molecular biology and evolution 21(6): 10851094.

6. Firoozeh, F., M. Saffari, F. Neamati and M. Zibaei (2014). "Detection of virulence genes in Escherichia coli isolated from patients with cystitis and pyelonephritis." Int J Infect Dis 29: 219-222.

7. Flores-Mireles, A. L., J. N. Walker, M. Caparon and S. J. Hultgren (2015). "Urinary tract infections: epidemiology, mechanisms of infection and treatment options." Nat Rev Microbiol 13(5): 269-284.

8. Geerlings, S. E. (2016). "Clinical Presentations and Epidemiology of Urinary Tract Infections." Microbiol Spectr 4(5).

9. Gupta, K., T. M. Hooton, K. G. Naber, B. Wullt, R. Colgan, L. G. Miller, G. J. Moran, L. E. Nicolle, R. Raz, A. J. Schaeffer and D. E. Soper (2011). "International clinical practice guidelines for the treatment of acute uncomplicated cystitis and pyelonephritis in women: A 2010 update by the Infectious Diseases Society of America and the European Society for Microbiology and Infectious Diseases." Clinical infectious diseases : an official publication of the Infectious Diseases Society of America 52(5): e103-120.

10. Hamdan, H. Z., E. Kubbara, A. M. Adam, O. S. Hassan, S. O. Suliman and I. Adam (2015). "Urinary tract infections and antimicrobial sensitivity among diabetic patients at Khartoum, Sudan." Ann Clin Microbiol Antimicrob 14: 26.

11. Harrington, S. M., M. C. Strauman, C. M. Abe and J. P. Nataro (2005). "Aggregative adherence fimbriae contribute to the inflammatory response of epithelial cells infected with enteroaggregative Escherichia coli." Cell Microbiol 7(11): 1565-1578.

12. Hernandez-Vergara, J. A., V. I. Martinez-Santos, R. B. Radilla-Vazquez, J. Silva-Sanchez, A. Vences-Velasquez and N. Castro-Alarcon (2016). "Characterization of Escherichia coli clinical isolates causing urinary tract infections in the community of Chilpancingo, Mexico." Int Microbiol 19(4): 209-215.

13. Herzog, K., J. Engeler Dusel, M. Hugentobler, L. Beutin, G. Sagesser, R. Stephan, H. Hachler and M. Nuesch-Inderbinen (2013). "Diarrheagenic enteroaggregative Escherichia coli causing urinary tract infection and bacteremia leading to sepsis." Infection 42(2): 441-444.

14. Hicks, S., D. C. Candy and A. D. Phillips (1996). "Adhesion of enteroaggregative Escherichia coli to pediatric intestinal mucosa in vitro." Infect Immun 64(11): 4751-4760.

15. Huang, D. B., J. A. Mohamed, J. P. Nataro, H. L. DuPont, Z. D. Jiang and P. C. Okhuysen (2007). "Virulence characteristics and the molecular epidemiology of enteroaggregative Escherichia coli isolates from travellers to developing countries." J Med Microbiol 56(Pt 10): 1386-1392.

16. Imuta, N., T. Ooka, K. Seto, R. Kawahara, T. Koriyama, T. Kojyo, A. Iguchi, K. Tokuda, H. Kawamura, K. Yoshiie, Y. Ogura, T. Hayashi and J. Nishi (2016). "Phylogenetic Analysis of Enteroaggregative Escherichia coli (EAEC) Isolates from Japan Reveals Emergence of 
CTX-M-14-Producing EAEC O25:H4 Clones Related to Sequence Type 131." Journal of clinical microbiology 54(8): 2128-2134.

17. Johnson, J. R. (1991). "Virulence factors in Escherichia coli urinary tract infection." Clinical microbiology reviews 4(1): 80-128.

18. Kaper, J. B., J. P. Nataro and H. L. Mobley (2004). "Pathogenic Escherichia coli." Nat Rev Microbiol 2(2): 123-140.

19. Lara, F. B., D. R. Nery, P. M. de Oliveira, M. L. Araujo, F. R. Carvalho, L. C. Messias-Silva, L. B. Ferreira, C. Faria-Junior and A. L. Pereira (2017). "Virulence Markers and Phylogenetic Analysis of Escherichia coli Strains with Hybrid EAEC/UPEC Genotypes Recovered from Sporadic Cases of Extraintestinal Infections." Front Microbiol 8: 146.

20. Marrs, C. F., L. Zhang and B. Foxman (2005). "Escherichia coli mediated urinary tract infections: are there distinct uropathogenic E. coli (UPEC) pathotypes?" FEMS Microbiol Lett 252(2): 183-190.

21. Mohamed, J. A., D. B. Huang, Z. D. Jiang, H. L. DuPont, J. P. Nataro, J. Belkind-Gerson and P. C. Okhuysen (2007). "Association of putative enteroaggregative Escherichia coli virulence genes and biofilm production in isolates from travelers to developing countries." J Clin Microbiol 45(1): 121-126.

22. Nicolle, L. E. (2005). "Urinary tract infection in diabetes." Curr Opin Infect Dis 18(1): 49-53.

23. Nishi, J., J. Sheikh, K. Mizuguchi, B. Luisi, V. Burland, A. Boutin, D. J. Rose, F. R. Blattner and J. P. Nataro (2003). "The export of coat protein from enteroaggregative Escherichia coli by a specific ATP-binding cassette transporter system." J Biol Chem 278(46): 4568045689.

24. Olesen, B., F. Scheutz, R. L. Andersen, M. Menard, N. Boisen, B. Johnston, D. S. Hansen, K. A. Krogfelt, J. P. Nataro and J. R. Johnson (2012). "Enteroaggregative Escherichia coli O78:H10, the cause of an outbreak of urinary tract infection." J Clin Microbiol 50(11): 3703-3711.

25. Park, H. K., Y. J. Jung, H. C. Chae, Y. J. Shin, S. Y. Woo, H. S. Park and S. J. Lee (2009). "Comparison of Escherichia coli uropathogenic genes (kps, usp and ireA) and enteroaggregative genes (aggR and aap) via multiplex polymerase chain reaction from suprapubic urine specimens of young children with fever." Scand J Urol Nephrol 43(1): 51-57.

26. Salmani, H., A. Azarnezhad, M. R. Fayazi and A. Hosseini (2016). "Pathotypic and Phylogenetic Study of Diarrheagenic Escherichia coli and Uropathogenic E. coli Using Multiplex Polymerase Chain Reaction." Jundishapur J Microbiol 9(2): e28331.

27. Salud, S. d. (2017). Anuarios de Morbilidad 1984-2017. Estados Unidos Mexicanos, Dirección General de Epidemiología de México- Dirección General Adjunta de Epidemiología.

28. Sheikh, J., J. R. Czeczulin, S. Harrington, S. Hicks, I. R. Henderson, C. Le Bouguenec, P. Gounon, A. Phillips and J. P. Nataro (2002). "A novel dispersin protein in enteroaggregative Escherichia coli." J Clin Invest 110(9): 1329-1337.

29. Smelov, V., K. Naber and T. E. B. Johansen (2016). "Improved classification of urinary tract infection: Future considerations." European Association or Urology 15(49): 71-80.

30. Smith, M. A., R. A. Weingarten, L. M. Russo, C. L. Ventura and A. D. O'Brien (2015). "Antibodies against hemolysin and cytotoxic necrotizing factor type 1 (CNF1) reduce bladder inflammation in a mouse model of urinary tract infection with toxigenic uropathogenic Escherichia coli." Infect Immun 83(4): 1661-1673. 
388 31. Soto, S. M. (2014). "Importance of biofilms in urinary tract infections: new therapeutic approaches." Advances in Biology 2014: 13.

32. Stepanovic, S., D. Vukovic, V. Hola, G. Di Bonaventura, S. Djukic, I. Cirkovic and F. Ruzicka (2007). "Quantification of biofilm in microtiter plates: overview of testing conditions and practical recommendations for assessment of biofilm production by staphylococci." APMIS 115(8): 891-899.

33. Toval, F., C. D. Kohler, U. Vogel, F. Wagenlehner, A. Mellmann, A. Fruth, M. A. Schmidt, H. Karch, M. Bielaszewska and U. Dobrindt (2013). "Characterization of Escherichia coli isolates from hospital inpatients or outpatients with urinary tract infection." $\underline{\mathrm{J} \text { Clin }}$ Microbiol 52(2): 407-418.

34. Zacche, M. M. and I. Giarenis (2016). "Therapies in early development for the treatment of urinary tract inflammation." Expert opinion on investigational drugs 25(5): 531-540.

35. Zhang, R., D. X. Gu, Y. L. Huang, E. W. Chan, G. X. Chen and S. Chen (2016). "Comparative genetic characterization of Enteroaggregative Escherichia coli strains recovered from clinical and non-clinical settings." Sci Rep 6: 24321. 
Figure 1

Distribution of phylogenetic groups of UPEC and UPEC/EAEC isolates

Data in percentage. * Fisher's exact test. p value $<0.05$ was considered statistically significant. 


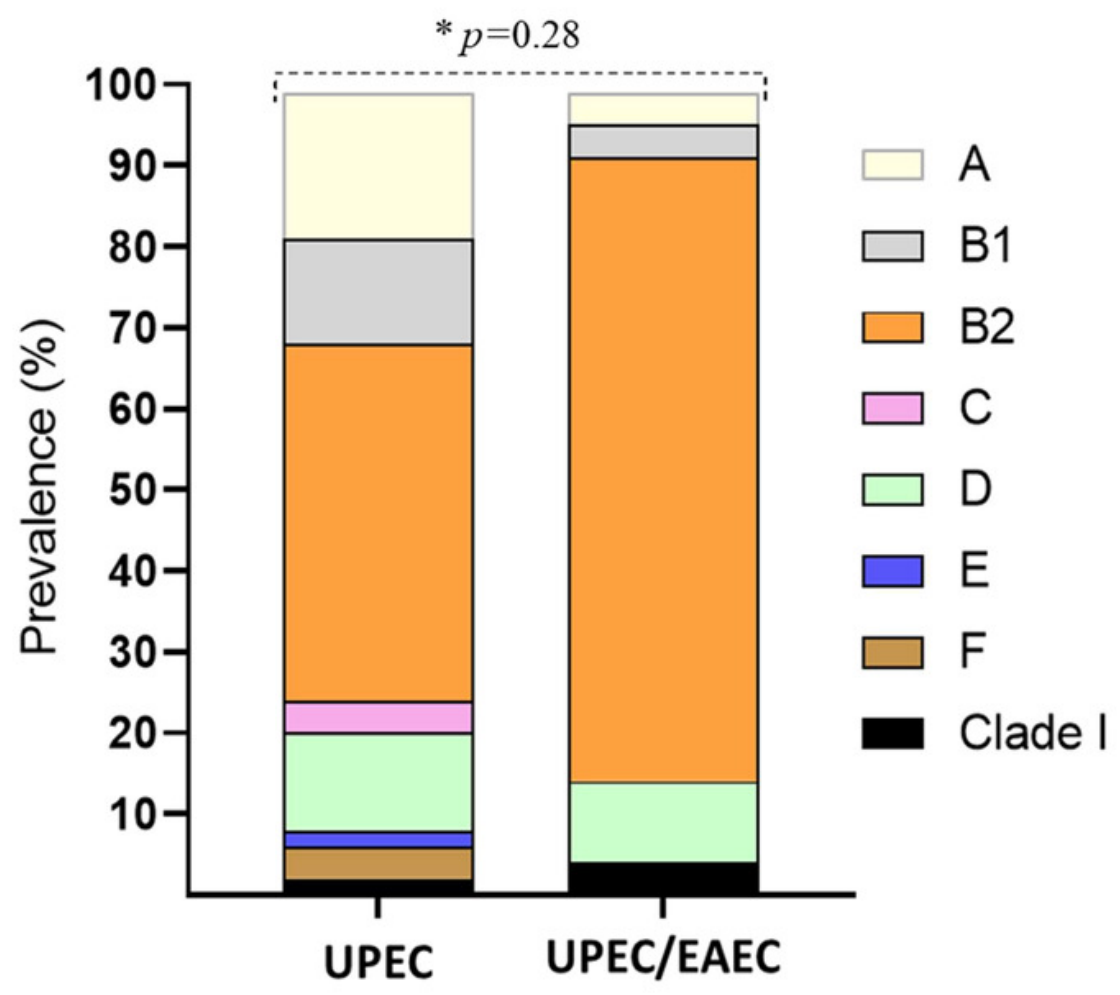




\section{Table 1 (on next page)}

Oligonucleotides used in this study 
1 Table 1. Oligonucleotides used in this study.

2

\begin{tabular}{|c|c|c|c|}
\hline Gene & Oligonucleotide sequence ( $\left(5^{\prime}-3^{\prime}\right)$ & Product size & Reference \\
\hline hly $A$ & $\begin{array}{l}\text { AACAAGGATAAGCACTGTTCTGGCT } \\
\text { ACCATATAAGCGGTCATTCCCGTCA }\end{array}$ & 1177 & $(23)$ \\
\hline fimH & $\begin{array}{l}\text { TGCAGAACGGATAAGCCGTGG } \\
\text { GCAGTCACCTGCCCTCCGGTA }\end{array}$ & 508 & (24) \\
\hline papC & $\begin{array}{l}\text { GTGGCAGTATGAGTAATGACCGTTA } \\
\text { ATATCCTTTCTGCAGGGATGCAATA }\end{array}$ & 200 & $\begin{array}{l}(24) \\
(25)\end{array}$ \\
\hline iutA & $\begin{array}{l}\text { GGCTGGACATCATGGGAACTGG } \\
\text { CGTCGGGAACGGGTAGAATCG }\end{array}$ & 300 & (26) \\
\hline cnfl & $\begin{array}{l}\text { AAGATGGAGTTTCCTATGCAGGAG } \\
\text { CATTCAGAGTCCTGCCCTCATTATT }\end{array}$ & 498 & $(23)$ \\
\hline aap & $\begin{array}{l}\text { CTTGGGTATCAGCCTGAATG } \\
\text { AACCCATTCGGTTAGAGCAC }\end{array}$ & 310 & $(27)$ \\
\hline $\operatorname{agg} R$ & $\begin{array}{l}\text { CTAATTGTACAATCGATGTA } \\
\text { AGAGTCCATCTCTTTGATAAG }\end{array}$ & 457 & $(27)$ \\
\hline aatA & $\begin{array}{l}\text { CTGGCGAAAGACTGTATCAT } \\
\text { CAATGTATAGAAATCCGCTGTT }\end{array}$ & 629 & $(27)$ \\
\hline
\end{tabular}

3

4 


\section{Table 2 (on next page)}

Clinical and demographic characteristics of the population associated with $E$. coli pathotypes.

Data in $\mathrm{n}$ (percentage). * Fisher's exact test. $\mathrm{p}$ value $<0.05$ was considered statistically significant. 
1 Table 2. Clinical and demographic characteristics of the population associated with E. coli pathotypes.

2

3

\begin{tabular}{|c|c|c|c|c|}
\hline Variables & $\begin{array}{c}\text { Total } \\
\text { n=99 (\%) }\end{array}$ & $\begin{array}{c}\text { UPEC } \\
\mathrm{n}=77(\%)\end{array}$ & $\begin{array}{c}\text { UPEC/EAEC } \\
\text { n=22 (\%) }\end{array}$ & $p$ value * \\
\hline \multicolumn{5}{|l|}{ Sex } \\
\hline Male & $23(23.33)$ & $17(22.08)$ & $6(27.27)$ & 0.58 \\
\hline Female & $76(76.77)$ & $60(77.92)$ & $16(72.73)$ & \\
\hline \multicolumn{5}{|l|}{ Age (years) } \\
\hline Underage (0-17) & $4(4.04)$ & $4(5.19)$ & 0 & 0.22 \\
\hline Young adults (18-34) & $7(7.07)$ & $7(9.09)$ & 0 & \\
\hline Older adults (35-59) & $42(42.42)$ & $29(37.66)$ & $13(59.09)$ & \\
\hline Elderly $(\geq 60)$ & $46(46.46)$ & $37(48.05)$ & $9(40.91)$ & \\
\hline \multicolumn{5}{|l|}{ UTIs-associated risk factors } \\
\hline None & $66(66.67)$ & $53(68.83)$ & $13(59.09)$ & 0.63 \\
\hline Type 2 Diabetes & $21(21.21)$ & $14(18.18)$ & $7(31.82)$ & \\
\hline Type 2 Diabetes-Chronic renal failure & $5(5.05)$ & $4(5.19)$ & $1(4.55)$ & \\
\hline Chronic renal failure & $3(3.03)$ & $2(2.60)$ & $1(1.55)$ & \\
\hline Catheter & $3(3.03)$ & $3(3.90)$ & 0 & \\
\hline Pregnancy & $1(1.01)$ & $1(1.30)$ & 0 & \\
\hline \multicolumn{5}{|l|}{ Clinic symptomatology } \\
\hline Asymptomatic & $54(54.55)$ & $46(59.74)$ & $8(36.36)$ & 0.08 \\
\hline Symptomatic & $45(45.45)$ & $31(40.26)$ & $14(63.64)$ & \\
\hline \multicolumn{5}{|l|}{ Infections } \\
\hline Asymptomatic bacteriuria & $54(54.55)$ & $46(59.74)$ & $8(36.36)$ & 0.15 \\
\hline Cystitis & $25(25.25)$ & $17(22.08)$ & $8(36.36)$ & \\
\hline Pyelonephritis & $20(20)$ & $14(18.18)$ & $6(27.27)$ & \\
\hline
\end{tabular}

4
5

Data in $\mathrm{n}$ (percentage). * Fisher's exact test. $\mathrm{p}$ value $<0.05$ was considered statistically significant. 


\section{Table 3(on next page)}

Distribution of EAEC and UPEC virulence genes in strains isolated from asymptomatic and symptomatic patients

Data in $\mathrm{n}$ (percentage). * Fisher's exact test. $p<0.05$ was considered statistically significant. 
1 Table 3. Distribution of EAEC and UPEC virulence genes in strains isolated from asymptomatic 2 and symptomatic patients.

3

4

\begin{tabular}{|c|c|c|c|c|}
\hline & $\begin{array}{c}\text { Total } \\
\mathbf{n}=99(\%)\end{array}$ & $\begin{array}{l}\text { Asymptomatic } \\
\text { n=54 (\%) }\end{array}$ & $\begin{array}{c}\text { Symptomatic } \\
n=45(\%)\end{array}$ & $p$ value * \\
\hline \multicolumn{5}{|c|}{ EAEC genes } \\
\hline aat $A$ & $14(14)$ & $4(7)$ & $10(22)$ & 0.045 \\
\hline $\operatorname{agg} R$ & $22(22)$ & $8(15)$ & $14(31)$ & 0.088 \\
\hline $\operatorname{aap} A$ & $23(23)$ & $12(22)$ & $11(24)$ & 0.815 \\
\hline \multicolumn{5}{|c|}{ UPEC genes } \\
\hline papC & $37(37)$ & $17(31)$ & $20(44)$ & 0.214 \\
\hline iutA & $66(67)$ & $36(67)$ & $30(67)$ & 1.000 \\
\hline $\operatorname{fim} H$ & $84(85)$ & $44(81)$ & $40(89)$ & 0.402 \\
\hline cnf1 & $24(24)$ & $8(15)$ & $16(36)$ & 0.020 \\
\hline$h l y A$ & $15(15)$ & $3(6)$ & $12(27)$ & 0.005 \\
\hline
\end{tabular}

5

6 Data in $\mathrm{n}$ (percentage). * Fisher's exact test. $p<0.05$ was considered statistically significant. 


\section{Table 4 (on next page)}

Association between EAEC and UPEC virulence genes and clinical infection

Data in $\mathrm{n}$ (percentage). * Fisher's exact test. $p<0.05$ was considered statistically significant. †Multivariate analysis adjusted by age and gender. Reference category was AB infection presence and negative gene presence. $A B$ : asymptomatic bacteriuria. 
1 Table 4. Association between EAEC and UPEC virulence genes and clinical infection.

2

3

\begin{tabular}{|c|c|c|c|c|c|c|c|}
\hline EAEC genes & $\begin{array}{c}\text { Total } \\
\text { n=99 (\%) }\end{array}$ & $\begin{array}{c}\text { AB } \\
n=54(\%)\end{array}$ & $\begin{array}{c}\text { Cystitis } \\
\text { n=25 (\%) }\end{array}$ & $\begin{array}{c}\text { Pyelonephritis } \\
\text { n=20 (\%) }\end{array}$ & $\begin{array}{c}p \\
\text { value* }\end{array}$ & $\begin{array}{c}\text { Cystitis } \\
\text { OR, CI 95\%, } p \text { value } \uparrow\end{array}$ & $\begin{array}{c}\text { Pyelonephritis } \\
\text { OR, CI 95\%, } p \text { value } \dagger\end{array}$ \\
\hline aatA+ & $14(14)$ & $4(7)$ & $5(20)$ & $5(25)$ & 0.077 & $4.43(0.92-21.29) 0.063$ & $5.15(1.09-24.32) 0.038$ \\
\hline $\operatorname{agg} R+$ & $22(22)$ & $8(15)$ & $8(32)$ & $6(30)$ & 0.151 & $2.99(0.85-10.39) 0.085$ & $2.95(0.82-10.50) 0.095$ \\
\hline $\operatorname{aap} A^{+}$ & $23(23)$ & $12(22)$ & $8(32)$ & $3(15)$ & 0.428 & $1.51(0.48-4.74) 0.473$ & $0.62(0.15-2.55) 0.516$ \\
\hline \multicolumn{8}{|l|}{ UPEC genes } \\
\hline papC+ & $37(37)$ & $17(31)$ & $9(36)$ & $10(55)$ & 0.175 & $0.81(0.27-2.41) 0.707$ & $2.30(0.79-6.73) 0.126$ \\
\hline iutA+ & $66(67)$ & $36(67)$ & $16(64)$ & $14(70)$ & 0.920 & $0.87(0.30-2.50) 0.806$ & $1.36(0.43-4.23) 0.591$ \\
\hline fimH+ & $84(85)$ & $44(81)$ & $22(88)$ & $18(90)$ & 0.603 & $1.42(0.33-6.14) 0.633$ & $1.70(0.32-899) 0.532$ \\
\hline cnf1+ & $24(24)$ & $8(15)$ & $7(28)$ & $9(45)$ & 0.026 & $2.08(0.63-6.82) 0.224$ & $4.22(1.30-13.64) 0.016$ \\
\hline hly $A+$ & $15(15)$ & $3(6)$ & $5(20)$ & $7(35)$ & 0.004 & $3.71(0.78-17.48) 0.097$ & $8.25(1.83-37.21) 0.006$ \\
\hline \multicolumn{8}{|c|}{ Biofilm production } \\
\hline High & $21(21)$ & $10(19)$ & $5(21)$ & $6(32)$ & 0.564 & $1.29(0.36-4.56) 0.701$ & $2.06(0.61-6.92) 0.243$ \\
\hline
\end{tabular}

4

5 Data in $\mathrm{n}$ (percentage). * Fisher's exact test. $p<0.05$ was considered statistically significant. $\dagger$ Multivariate analysis 6 adjusted by age and gender. Reference category was AB infection presence and negative gene presence. AB:

7 asymptomatic bacteriuria. 


\section{Table 5 (on next page)}

Antibiotic resistance, ESBL production and biofilm production of clinical isolates.

Data in $\mathrm{n}$ (percent). * Fisher's exact test. $p<0.05$ was considered statistically significant. 
1 Table 5. Antibiotic resistance, ESBL production and biofilm production of clinical isolates.

2

\begin{tabular}{|c|c|c|c|c|c|}
\hline \multicolumn{2}{|l|}{ Antibiotics } & $\begin{array}{c}\text { Total } \\
\text { n=99 (\%) }\end{array}$ & $\begin{array}{c}\text { UPEC } \\
\mathbf{n}=77(\%)\end{array}$ & $\begin{array}{c}\text { UPEC/EAEC } \\
n=22(\%)\end{array}$ & $p$ value * \\
\hline \multirow[t]{2}{*}{ Ampicillin } & $\mathrm{R}$ & $80(80.81)$ & $61(79.22)$ & $19(86.36)$ & 0.55 \\
\hline & S & $19(19.19)$ & $16(20.78)$ & $2(13.64)$ & \\
\hline \multirow[t]{2}{*}{ Ampicillin/Sulbactam } & $\mathrm{R}$ & $70(70.71)$ & $52(67.53)$ & $18(81.81)$ & 0.28 \\
\hline & $\mathrm{S}$ & $29(29.29)$ & $25(32.47)$ & $4(18.18)$ & \\
\hline \multirow[t]{2}{*}{ Cefazoline } & $\mathrm{R}$ & $52(52.53)$ & $35(45.45)$ & $17(77.27)$ & 0.014 \\
\hline & $\mathrm{S}$ & $47(47.47)$ & $42(54.55)$ & $5(22.73)$ & \\
\hline \multirow[t]{2}{*}{ Ceftriaxone } & $\mathrm{R}$ & $47(47.47)$ & $30(38.96)$ & $17(77.27)$ & 0.002 \\
\hline & S & $52(52.53)$ & $47(61.04)$ & $5(22.73)$ & \\
\hline \multirow[t]{2}{*}{ Cefepime } & $\mathrm{R}$ & $45(45.45)$ & $28(36.36)$ & $17(77.27)$ & 0.001 \\
\hline & S & $54(54.55)$ & $49(63.64)$ & $5(22.73)$ & \\
\hline \multirow[t]{2}{*}{ Aztreonam } & $\mathrm{R}$ & $47(47.47)$ & $30(38.96)$ & $17(77.27)$ & 0.002 \\
\hline & S & $52(52.53)$ & $47(61.04)$ & $5(22.73)$ & \\
\hline \multirow[t]{2}{*}{ Amikacin } & $\mathrm{R}$ & $2(2.02)$ & $1(1.30)$ & $1(4.55)$ & 0.39 \\
\hline & $\mathrm{S}$ & $97(97.98)$ & $76(98.70)$ & $21(95.45)$ & \\
\hline \multirow[t]{2}{*}{ Gentamicin } & $\mathrm{R}$ & $38(38.38)$ & $27(35.06)$ & $11(50)$ & 0.22 \\
\hline & $\mathrm{S}$ & $61(61.62)$ & $50(64.94)$ & $11(50)$ & \\
\hline \multirow[t]{2}{*}{ Tobramycin } & $\mathrm{R}$ & $45(45.45)$ & $30(38.96)$ & $15(68.18)$ & 0.027 \\
\hline & $\mathrm{S}$ & $54(54.55)$ & $47(61.04)$ & $7(31.82)$ & \\
\hline \multirow[t]{2}{*}{ Ciprofloxacin } & $\mathrm{R}$ & $67(67.68)$ & $48(62.34)$ & $19(86.36)$ & 0.040 \\
\hline & $\mathrm{S}$ & $32(32.32)$ & $29(37.66)$ & $3(13.64)$ & \\
\hline \multirow[t]{2}{*}{ Nitrofurantoin } & $\mathrm{R}$ & $17(17.17)$ & $14(18.18)$ & $3(13.64)$ & 0.75 \\
\hline & $\mathrm{S}$ & $82(82.83)$ & $63(81.82)$ & $19(86.36)$ & \\
\hline \multirow[t]{2}{*}{ Trimethoprim/Sulfamethoxazole } & $\mathrm{R}$ & $60(60.61)$ & $47(61.04)$ & $13(59.09)$ & 1.00 \\
\hline & $\mathrm{S}$ & $39(39.39)$ & $30(38.96)$ & $9(40.91)$ & \\
\hline \multirow[t]{2}{*}{ ESBL } & Negative & $53(53.54)$ & $48(62.34)$ & $5(22.73)$ & 0.001 \\
\hline & Positive & $46(46.46)$ & $29(37.66)$ & $17(77.27)$ & \\
\hline \multirow[t]{2}{*}{ MDR } & $\leq 2$ drugs & $30(30.30)$ & $28(36.36)$ & $2(9.09)$ & 0.017 \\
\hline & $\geq 3$ drugs & $69(69.70)$ & $49(63.64)$ & $20(90.91)$ & \\
\hline \multirow[t]{2}{*}{ Biofilm } & Low & $74(77.89)$ & $58(77.33)$ & $16(80)$ & 0.532 \\
\hline & High & $21(22.11)$ & $17(22.67)$ & $4(20)$ & \\
\hline
\end{tabular}

3

4 Data in $\mathrm{n}$ (percent). * Fisher's exact test. $p<0.05$ was considered statistically significant. 